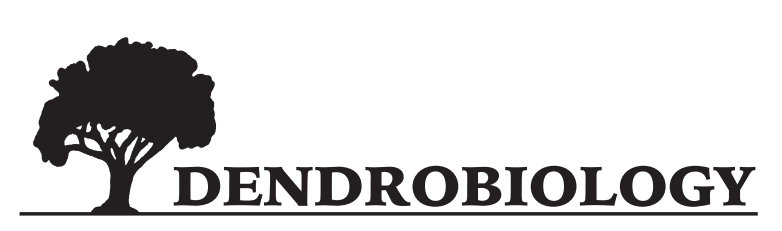

2018, vol. 79, 156-167

http://dx.doi.org/10.12657/denbio.079.014

\author{
Hongfang Wen, Xiangwen Deng*, Yifei Zhang, Xiaocong Wei, \\ Guangjun Wang, Bo Zhou, Wenhua Xiang, Ninghua Zhu
}

\title{
Cunninghamia lanceolata variant with red-heart wood: a mini-review
}

Received: 23 October 2017; Accepted: 25 April 2018

\begin{abstract}
Chinese fir (Cunninghamia lanceolata) is one of the most important tree species in the ecology and economy of China. This conifer has produced many cultivars following a long period of lineage divergence. Red-heart Chinese fir is a variant of Cunninghamia lanceolata, with many special characteristics and worth to promote. Some studies have shown that this excellent variant originated in Jiangxi Province.

This review introduces the red-heart Chinese fir to the world and focuses on the characteristics and the economic value of this taxon.

Red-heart Chinese fir is famous for the possession of a shiny, chestnut brown xylem that sorrouds the pith; the red-heart wood ratio of this species is more than $50.5 \%$, and can be as high as $80 \%$ in mature forests. The red-heart characteristics increases this tree's value, while simultaneously decreasing the value of timber from some other species with red-heart wood, for example, Fagus sylvatica. Previous research on red-heart Chinese fir has focused on its cultivation, value and utilization, including methods of propagation, genetic resources, its chemical composition and wood application. The mechanisms that underlie the formation of these characteristics, however, have seldom been researched and discussed. Although redheart Chinese fir is one of the most valuable variants of $C$. lanceolata, the formation of this species has been neglected. The conclusion of this review comprises a perspective on future research, including how genetics and environment affect the formation of red-heart in Chinese fir. The relationships between the formation of red-heart Chinese fir and the properties of cambium and ray cell walls as well as other cells in the stem are important research gaps in this taxon.
\end{abstract}

Keywords: forest plantation, red-heart Chinese fir wood, genetic resources, chemical composition, timber character

Addresses: H. F. Wen, X. W. Deng, Y. F. Zhang, X. C. Wei, G. J. Wang, B. Zhou, W. H. Xiang, College of Life Science and Technology, Central South University of Forestry and Technology, Changsha, 410004, China, e-mail: dxwfree@126.com

X. W. Deng, G. J. Wang, W. H. Xiang, National Engineering Laboratory for Applied Technology of Forestry \& Ecology in South China, Changsha, 410004, China

N. H. Zhu, College of Forestry, Central South University of Forestry and Technology, Changsha, 410004, China 


\section{Introduction}

Cunninghamia lanceolata (Chinese fir) cultivation has a history that extends back at least 1,600 years in China (Huang \& Lan, 1988; Yu et al., 1997; Ma, 2014). There were two cultivation patterns of $C$. lanceolata during the period from $813 \mathrm{AD}$ to 1949: the first pattern included pure stands of $C$. lanceolata, and the second when the trees were interspersed with crops (Yu et al., 1992; Ma \& Fan, 1993). This conifer is the most important softwood tree species and is grown across large areas in southern China (Zhang et al., 2013). Because C. lanceolata is a significant commercial species appreciated for its high quality timber, it plays an important role in the production practice of plantation (Yu, 1997b; Li et al., 2015). This species plays a pivotal role in fixing carbon (C) from the atmosphere. This conifer accumulates numerous chemical components, such as nitrogen $(\mathrm{N})$ and phosphorus $(\mathrm{P})$, which are subsequently released into the soil (Chen, 1998; Tian, 2005; Wen et al., 2014). The area of C. lanceolata plantations in 2014 was $1,096 \times 10^{4}$ ha, and accounted for $6.66 \%$ of the total forest plantation area nationwide. Similarly, in 2014, the plantation volume of $C$. lanceolata was $7.26 \times 10^{7} \mathrm{~m}^{3}$, and $4.91 \%$ out of the total wood volume nationwide; both the area and volume of $C$. lanceolata plantations have rapidly increased over recent decades (State Forestry Administration of China, 2014).

However, a large body of international research has shown that successive rotation of plantations can lead to a decline in stand productivity (Woods, 1990; O’Hehir et al., 2010; Halbritter \& Deegen, 2011; Xu et al., 2015). Previous research on this species has caused suggestions that the productivity of $C$. lanceolata declines during the second or third rotation, while a large volume of field observations suggest that the growth of this species also declines significantly when it is replanted in existing woodlands (Ding \& Chen, 1995; Chen, 1998; Bi et al., 2002; Tian et al., 2011; Xia et al., 2015). However Tian et al. (2011) suggest that the productivity of $C$. lanceolata would not decrease if the harvesting time of the second or third rotation is prolonged. Nonetheless, the reasons that underlay productivity decline in C. lanceolata are complex and include autotoxicity, changes in weather, associated undergrowth, and management practices such as slash burning, and so on. At present, the dominant factors thought to explain the decline in productivity, include the allelopathy of $C$. lanceolata over successive plantation rotations, as well as the fact that fine root biomass, root surface, and root length density are significantly reduced in second rotation plantations because the roots of the first generation leave a residual phytotoxicity (Huang et al., 2000; Chen \& Wang, 2013; Xia et al., 2015). Indeed, allelochemicals and $\mathrm{N}$ cycling are key regulators of productivity in repeated plantation woodlands; $\mathrm{N}$ limitation is thought to be the most important factor responsible for yield decline, and it is a common problem in secondary forests in sub-tropical regions (Zhang, 1997; LeBauer \& Treseder, 2008). However, the influence of this element continues to be debated. Wu et al. (2011a) suggest that P might actually be the major growth-limiting factor in C. lanceolata plantations. In addition, water stress leads to the formation of narrower ring widths, and thus a decrease in timber volume (Wood, 2004; Tang et al., 2016), while slash burning directly decreases soil fertility, and therefore forest productivity declines indirectly (Ding \& Chen, 1995; Bi et al., 2002). It remains unclear whether, or not, the presence of undergrowth contributes to a reduction or increase in the productivity of $C$. lanceolata plantations (Bi et al., 2002). The question remains whether the use of different variants of $C$. lanceolata in the second and third rotation would prevent productivity decline in plantations of this species.

In the context of global climate change, timber plantations play an increasingly important role in national economies and social development around the world (Pirard et al., 2016; Verheyen et al., 2016). C. lanceolata is one of the principal cultivated tree species in China. It is a particularly fast-growing timber species that is native to southern China. This conifer is highly productive, and has a straight and uniform trunk. It yields timber with an attractive grain and finish that is light, tough and moderately strong, as well as insect- and rot-resistant. Its wood has a pleasant aroma. As the dominant fast-growing cultivated timber species in southern China, this conifer is also distributed across numerous regions and has many cultivars, so the plantations of $C$. lanceolata are beneficial to the mitigation of climate change (Fang et al., 2001; Tian et al., 2011). The variants have their unique characteristics, such as wood with a red-heart that makes it more attractive and thus increases its value (Yang \& Zeng, 2003), and better physico-mechanical properties (Luo \& Xu, 1985; Duan et al., 2016a). The numerous variants have resulted from a long period of lineage divergence, some of which are presented below (Chen \& Shi, 1983; Li, 1989; Yu, 1994):

1. C. lanceolata 'E Sha1' (Fig. 1A) which was identified lately as a new cultigen of $C$. lanceolata by taxonomists in 2015, and has since become distinct following a long cultivation period from $C$. lanceolata 'Luotian' that was a particular cultigen of $C$. lanceolata. The external characteristics of this cultigen became clearly distinct at 20 years of age from those of other C. lanceolata forms, most notably the possession of a sharply conical crown; a narrow canopy between $1.0 \mathrm{~m}$ and $1.5 \mathrm{~m}$ and a crown length that was just $1.0 \mathrm{~m}$ when measured 


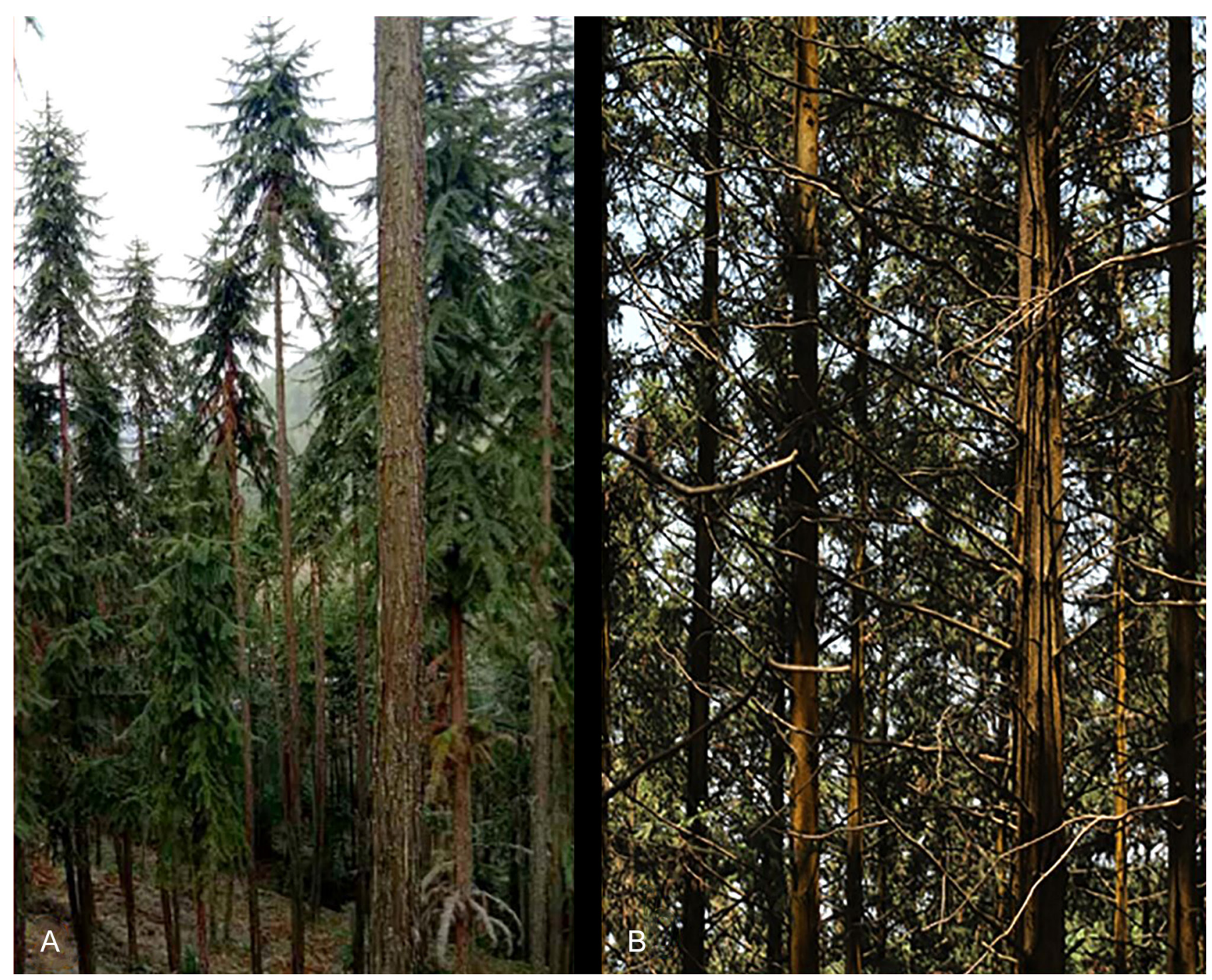

Fig. 1. Comparisons between the crown of Cunninghamia lanceolata 'E Sha1' and Chenshan red-heart Chinese fir, A - C. lanceolata 'E Sha1' (from Xu et al., 2015). B - Photo taken by Xiangwen Deng (2016) shows the crown of a Chenshan red-heart Chinese fir. This variant has a longer canopy length and larger crown than $\mathrm{A}$

from the top of the tree downwards. The angle between the upper stem and branch is 90 degrees in one or two-year-old examples, while this angle reaches 150 degrees in a three-year-old branch, indicating sagging. Branches stopped growing by four years of age, and their diameter at the attachment point with the trunk is just $1.0 \mathrm{~cm}$. Then during the late October of sixth year, the branches fall off the tree without leaving any scar on the trunk, and consequently without a detrimental effect on timber quality or percentage of outturn (Xu et al., 2016b). When compared to other variants of $C$. lanceolata, the above characters of this cultivar are unique.

2. C. lanceolata 'Glouca' is a cultigen with gray-green or blue-green (glaucous) leaves that have an obvious white powdery covering on both surfaces. This cultivar has a higher growth rate than C. lanceolata and can be found dispersed in the forest of other C. lanceolata (Luo \& Xu, 1985).
3. C. lanceolata 'Mollifolia' is a cultigen with thin and soft leaves which have obtuse apices. This variant originated from among C. lanceolata populations grown in Hunan and Yunan provinces (Fu et al., 1999).

4. C. lanceolata 'Youshan' is a cultigen with yellow-green and glossy young leaves. Its photosynthetic rate is higher than C. lanceolata 'Mangshan', but its growth rate is lower under similar conditions (Lei, 1988).

5. C. lanceolata 'Mangshan' is a cultigen where young leaves on branches are blue-green, but not glossy. Its wood has better economic properties than $C$. lanceolata 'Youshan' (Xu \& Wu, 1987; Lei, 1988).

6. C. lanceolata 'Konishii' is a unique cultigen form of $C$. lanceolata that grows in Taiwan. It has slightly blackened heartwood, and a strong fragrance (Liang, 2010).

7. C. lanceolata 'Viriclis' is a cultigen in which leaf color does not change in winter, and this charac- 

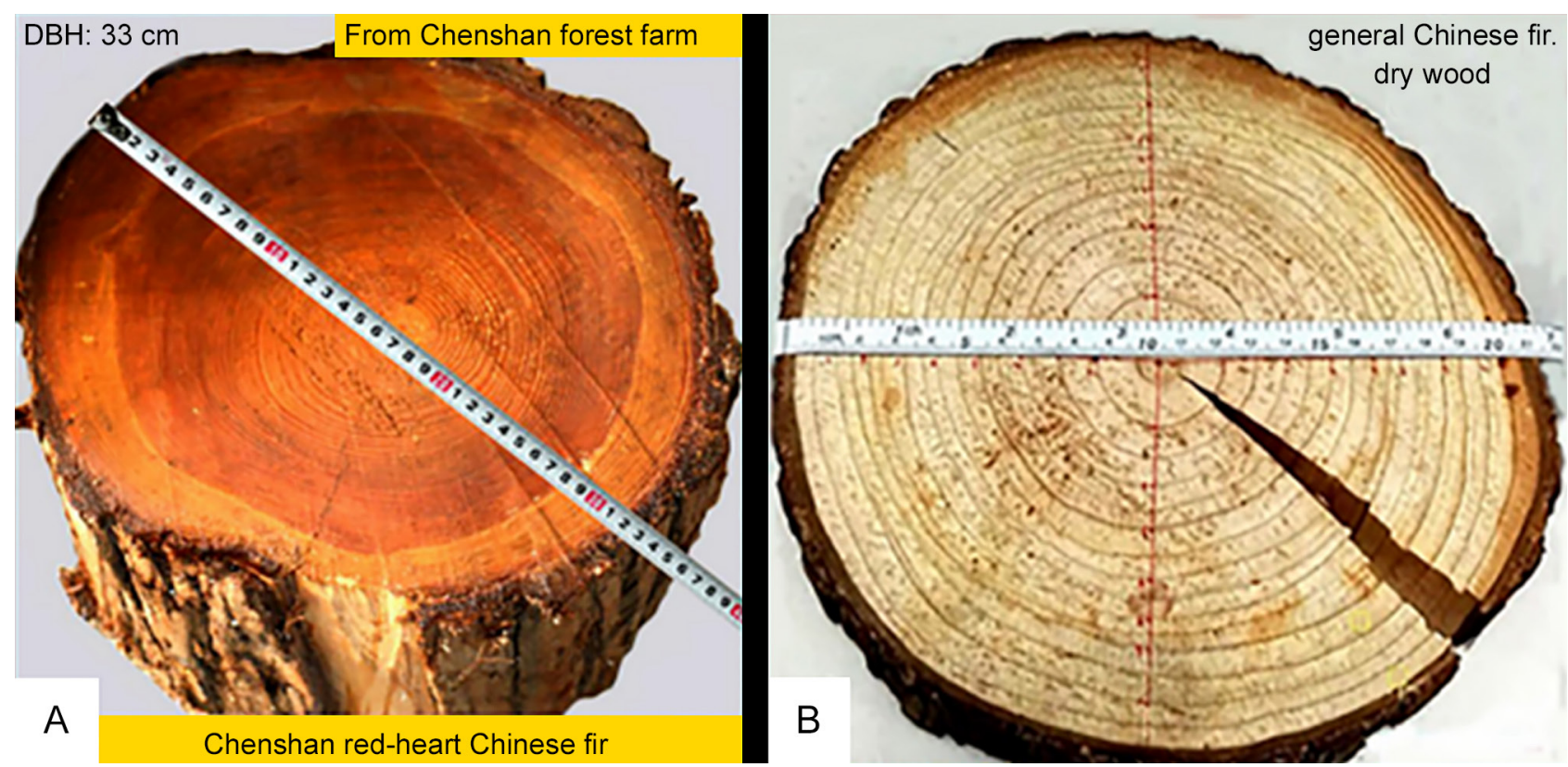

Fig. 2. Wood of Cunninghamia lanceolata photographed by Xiangwen Deng in 2016: A - red-heart Chinese fir, a unique fir species with a large proportion of red heartwood (ca. 80\%) in the Chenshan Forestry Station, Anfu County, Jiangxi Province; B - species of ordinary C. lanceolata without red heartwood; this specimen was cut from a stand in Huitong County, Hunan Province. In B, the timber can be seen to be prone to cracking and the shiny color is absent

ter could be stable through generation of self-fertilization (Chen \& Shi, 1983).

8. C. lanceolata var. monocaulis Yieh is a slow-growing cultigen that has a trunk with sparse leaves only, and without any branches (Chen \& Shi, 1983).

9. C. lanceolata (lamb.) Hook. var. corricosa has a longer fast-growth period, so it reaches maturity later than other $C$. lanceolata variants. This variant has quite a thick bark (Xu \& Fang, 1986; Li, 1989).

10.Red-heart Chinese fir (Fig. 1B) originated in Jiangxi Province and is well-known for the beautiful color of its heartwood - the xylem part that lies close to the pith, which is called red-heart (Fig. 2A). This cultigen has been rapidly propagated in recent years and now accounts for a large proportion of the total $C$. lanceolata plantations in China (Yang \& Zeng, 2003).

As a result of this variation, the unique red-heart Chinese fir variety has special economic status and importance. Compared with other C. lanceolata cultigens, this form has colored xylem which is finegrained, aromatic and tough with a high compressive resistance. The wood of this conifer is also rot-resistant and has a timber profile that includes a high proportion of red-heart wood. Because this proportion can be as high as $80 \%$ in mature red-heart Chinese fir forests (Fig. 2A); the variant was regarded as one of the best timbers with excellent weather and pathogen resistance for use in construction, furniture and decorative applications (Yang \& Zeng, 2003). Its yield is also superior and attractive. Indeed, the distinctive characteristics of this variant are likely to remain stable even if it is introduced to areas where other variants of $C$. lanceolata grow well, as its red-heart characteristic is strongly heritable (Yang \& Zeng, 2003). Because of the increasing number of construction projects and living standards across China, the demand for red-heart Chinese fir timber is also increasing; however, the availability of high-quality timber from this conifer remains limited because its current population is restricted to a narrow area.

Our aims in this paper are to introduce this taxon to the world and provide avenues for future research on the red-heart Chinese fir. For example, to determine how the red-heart character relates to the properties of cambium and ray cell walls as well as other cells in the stem; or, which factors would affect the red-heart ratio of red-heart Chinese fir? In order to meet market demands for this variety, further research is needed in the future.

\section{Literature review}

\section{Selection, breeding and propagule production}

\section{Selection and breeding}

Breeding for timber characteristics in response to industry requirements is an increasingly important objective that will lead to genetic improvement in C. lanceolata (Shi et al., 1993). A high level of genetic amelioration may facilitate improvements in 
commercially important traits, such as growth and wood-quality (Duan et al., 2016a). To date, however, the focus of current research on genetic and environmental influence on red-heart Chinese fir formation has mainly emphasized genetics, without reaching a definite conclusion about the formation of red-heart Chinese fir. Most of the traits are associated with, and regulated by multiple genes (Duan et al., 2016a). Chen et al. (2012) carried out research on genetic improvements of red-heart Chinese fir for different provenances and various geographic areas over many years. The results of this long-term study suggest that there is no obvious difference in the timber characteristics of red-heart Chinese fir with respect to location or provenance (Bao, 1998). Yang \& Zeng (2003) also concluded that the red-heart characteristics of these trees is highly stable and heritable. With such desirable features, the $C$. lanceolata cultigens, especially red-heart Chinese fir, could be considered for introduction to suitable sites, such as Vietnam. Recently, Duan et al. (2015) utilized 21 simple sequence repeat markers to investigate the genetic characteristics of red-heart Chinese fir samples from five sites in Guangxi Province. The results show that genes are not consistent between different sites, and reveal that the majority of red-heart Chinese fir genotypes are apparently not associated with geographic origin. Duan et al. (2015) were unable to find an explanation for the phenomenon in the current research, and an environmental influence on red-heart in C. lanceolata remaines unclear. Similar research has also been carried out in Guangdong Province where C. lanceolata genetic samples have been collected and conserved to compile a gene pool that provided foundation of elite germplasm (Huang et al., 2006). Although the red-heart feature in Chinese fir is heritable, it is still uncertain how the formation of red-heart Chinese fir is related to genetic variation, because correlational research is lacking. An investigation of the relationship between genetic variation and the red-heart wood formation of red-heart Chinese fir should be made in future studies.

High-quality seeds and seedlings are essential to improve forest quality and productivity, as well as to achieve the national 'great leap forward' in commercial forestry. C. lanceolata stands are the principal commercial forests in southern China. Yet, red-heart Chinese fir is superior because of its faster growth rate and higher timber yield; these traits are particularly evident in trees grown at Chenshan Forest Farm in Anfu County, Jiangxi Province. A number of researchers have investigated natural populations, seed-breeding and seedling cultivation of red-heart Chinese fir; of the available propagation methods, raising seedlings is preferred to growing trees from cuttings (Huang et al., 2009). Seed yield and quality in an orchard are determined based on pollen viability (Zhang, 2003). Wu et al. (2012) investigated the pollen of red-heart Chinese fir under various conditions and found that it germinated in a culture medium containing approximately $10 \mathrm{mg} / \mathrm{L}$ boric acid and $15 \%(\mathrm{w} / \mathrm{v})$ sucrose; however, the viability of the pollen declined with time. It is suggested that an orchard, with tree management focused on improving seed quality, for the production of red-heart Chinese fir seeds should be built in Chenshan according to the principle of matching species with site. The quality of these trees can also be improved by selection of the best seed sources over successive generations. Some successes have so far been achieved in the establishment of red-heart Chinese fir seed orchards in other provinces, and both first- and second-generation progeny have been produced. Unfortunately, the improved red-heart Chinese fir genotypes generated so far have not been able to satisfy the demand of an expanding timber market. Nevertheless, building on the advances made in seed selection, some progress has been achieved in the use of tissue culture technology as an alternative means of propagation (Chen et al., 2012).

\section{Plantlet propagation}

In previous experiment, a total of 40 elite C. lanceolata clones were selected and divided into five groups for cultivation in an experimental test plantation. Among those clones the growth rate of redheart Chinese fir is the $15^{\text {th }}$ (Yang \& Zeng, 2003). The clones were obtained from the Paiyashan Forest Farm, Jingzhou County, from the Institute of Forestry Science of Huitong and from You and Jianghua counties by Hunan Forestry Academy of Sciences. This academy has carried out 30 years of research on $C$. lanceolata, including embryonic callus breeding technology in red-heart Chinese fir. Huang et al. (2009), for example, studied the influence of different hormones on the growth of the embryonic callus; the results demonstrated a major difference in the effects of 1-naphthaleneacetic acid (NAA) between this phase and cell proliferation. Results also showed that during the induction phase, 2, 4-dichlorophenoxyacetic acid (2, 4-D) was more effective than NAA, while the latter chemical was more effective during the subculture phase. Embryonic callus growth was also depressed by treatment with 6-benzylaminopurine (6-BA). The absence of root formation was a key obstacle encountered following the embryonic callus period, and inadequate rooting was an obvious impediment to plantlet establishment. In an attempt to overcome this problem, various hormones and chemical treatments were applied, but only limited progress was made. Later, Xu et al. (2016a) investigated the influence of different culture media on the root growth of red-heart Chinese fir plantlets produced 
by microdissection. These researchers established that the key factors that affected root growth and chlorophyll content were, successively, indole-3-butyric acid (IBA) concentration, matrix properties and NAA concentration. This analysis laid the foundations for the future propagation of red-heart Chinese fir from cuttings and seedlings, while further studies on forestry planting techniques have demonstrated that seedling establishment and management influenced both growth and timber quality (Zeng \& Jiang, 2012). Thus, the selection of seedlings with a good genetic background combined with the use of cultivation practice adapted to local conditions are likely to improve the quality, yield, and profitability of redheart Chinese fir production (Mo, 2014).

\section{The chemical composition of red-heart Chinese fir}

Chemical components influence the physical and mechanical properties of wood, and its potential applications (Cheng, 1985). Indeed, the color of wood is also likely related to chemical composition; on this basis, heartwood and sapwood are the two main subdivisions of $C$. lanceolata (Table 1). The C. lanceolata contains many chemical components, in particular essential oils, of which the most abundant is cedrol, a terpene. When extracted from trees in vivo, the composition of this sesquiterpene varies by Chinese fir region, variants, analysis objectives and extraction methods, as well as other factors (Ye et al., 2005; Liu \& Zhong, 2013). Qin et al. (2004) focused on holocellulose, $\alpha$-cellulose, hemicellulose, lignin and acid-soluble lignin content as well as the relative proportion of holocellulose to lignin in C. lanceolata heartwood and sapwood. The results showed that holocellulose and hemicellulose content both initially rose, and then declined along the stem, while $\alpha$-cellulose content initially decreased, rose and then declined, in a longitudinal direction within sapwood. In the heartwood, holocellulose content initially declined, and then rose. On the contrary, the content of hemicellulose initially rose, and then declined; the variation of $\alpha$-cellulose content was similar to that in sapwood. Within each part of the trunk, lignin content in sapwood was higher than in heartwood; in sapwood the lignin content decreased with increasing height of the trunk but this decline was less pronounced in heartwood (Qin et al., 2004). Similarly, the content of acid-soluble lignin conformed to a similar trend to $\alpha$-cellulose; the ratio of holocellulose to lignin in both sapwood and heartwood varied with trunk height, but the rule of the variation tendency of the ratio was not obvious. Fan et al. (2015) confirmed the longitudinal distribution of chemical components of red-heart Chinese fir that had been reported earlier by Qin et al. (2004), while the lignin and hemicellulose contents were lower than for other variants of $C$. lanceolata, the holocellulose content of these trees was higher.

Additional research has demonstrated that the red-heart characteristics of red-heart Chinese fir are related to the lignin content. Although these compounds can be extracted using $1 \% \mathrm{NaOH}$ and are soluble in benzene-ethanol (Fan et al., 2001), those that are mainly responsible for the red-heart color remain unclear. To address this, Yang et al. (2016) used gas chromatography-mass spectrometry to characterize the chemical components of alcoholic extracts in sapwood and heartwood from both redheart and ordinary C. lanceolata trees that were 20 or 30 years old. The results of this study showed that extracts mainly contained cedrol and sclareol; in redheart Chinese fir, the levels of both compounds were higher in heartwood than in sapwood and increased with age. For both types of $C$. lanceolata and in both types of wood, the content of sclareol was several times higher than that of cedrol, even though the content of the latter was higher in heartwood than in sapwood. To date, just a handful of studies have been performed on the composition and properties of timber solvent extracts that have attracted limited attention from the wood-processing industry (Wu et al., 2011b). Davies et al. (2014) studied solvent extracts from Sequoia sempervirens and concluded that the compounds they extracted were likely responsible for improvement of natural timber durability. The identification and characterization of bioactive compounds in C. lanceolata and their potential exploitation are likely to benefit both the commercial forestry and the wood-processing industries.

Table 1. Comparisons between the chemical components of sapwood and heartwood in red-heart Chinese fir

\begin{tabular}{|c|c|c|c|}
\hline \multirow{2}{*}{ Chemical components } & \multicolumn{2}{|l|}{ Results } & \multirow{2}{*}{ References } \\
\hline & Sapwood & Heartwood & \\
\hline $\begin{array}{l}\text { Holocellulose } \\
\alpha \text {-cellulose }\end{array}$ & Contents declined as trunk height increased & The same as sapwood & \\
\hline Acid-soluble lignin & & & Fan et al., 2001 \\
\hline Hemicellulose & Content initially increased and then declined & The same as sapwood & Yang et al., 2016 \\
\hline Lignin content & Higher content & Lower content & \\
\hline Cedrol and sclareol & Lower content & Higher content & \\
\hline
\end{tabular}


Table 2. The influence of soil physicochemical property on red heartwood

\begin{tabular}{lll}
\hline \multicolumn{1}{c}{ Factors } & & \multicolumn{1}{c}{ Results } \\
\hline Soil and soil type & Fundamental to plant growth and nutrition. & Cardoso et al., 2013 \\
& Influenced biological growth and available P and OM content & Liu et al., 2016 \\
P and OM & Main factors influenced the chemical composition of plants & Sun et al., 2013 \\
N availability & Secondary factor influenced the chemical composition of plants & Sun et al., 2013 \\
P, K, N & Positively correlated with nutrient accumulation by plants & Guo et al., 2014 \\
\hline
\end{tabular}

Site conditions seem to be important for the chemical composition of red-heart Chinese fir (Table 2). Soil characteristics are fundamental for plant growth and nutrition, as well as interactions and exchanges with the diversity of soil organisms and bioactive substances (Cardoso et al., 2013). In terms of basic soil physicochemical characteristics, the availability of $\mathrm{P}$ and organic matter (OM) followed by the availability of $\mathrm{N}$ have been shown to be the main factors influencing the chemical composition and quality of plants (Sun et al., 2013). Although several Chinese research groups have studied the chemical composition of red-heart Chinese fir (Huang et al., 2006; Wu et al., 2012; Liu \& Zhong, 2013; Duan et al., 2015), the factors that influence chemical composition have scarcely been addressed. Nevertheless, some research relevant to red-heart wood has been reported for other species, notably Populus tomentosa (poplar), P. massoniana, and $\mathrm{Fa}$ gus sylvatica L. (beech) (Wu et al., 2012; Vek et al., 2013). However, the relationship between chemical composition and soil environment remains difficult to unravel, and more research is necessary in these areas.

Although some results have been published on C. lanceolata that related heartwood formation to the viscoelastic and hygroscopic properties of cell walls, as well as cambial activity and transmission pathways (Song et al., 2011, 2014; Wu et al., 2016), we suggest that future research should more closely address the relationships between the red-heart feature of Chinese fir and the properties of cambium and ray cells as well as other cells in the stem, and the formation of xylem (Dong et al., 2016).

\section{Applications of red-heart Chinese fir wood}

\section{Properties of red-heart wood}

In the case of red-heart Chinese fir, the heartwood deepens in color and becomes more extensive with age. Uniquely, this attribute occurs in combination with a straight trunk, good timber properties, and a close and attractive grain (Huang et al., 2006) (Fig. 2A). Thus, based on studies of $C$. lanceolata cultigens across China, red-heart Chinese fir is considered to be outstanding due to its proportion of red-heart wood ratio being uniquely high, generally up to $50.5 \%$, and even up to $80 \%$ in mature forests (Huang et al., 2006). It is considered superior to some other C. lanceolata cultivars in terms of a suite of mechanical properties, including trunk density, water content, compressive resistance strength along the grain, cleavage resistance and impact strength (Fig. 2AB). Fan et al. (2015) also report that cross-sectional and red-heart wood eccentricities, as well as timber density, were all unaffected when trees were introduced to Jiangle State Forest Farm in Fujian Province.

A number of other tree species are also known to produce red-heart wood (Table 3). These include Lechang Chinese fir which has a higher-than-normal proportion of reddish heartwood in its harvested trunk and this property enhances its commercial value (Duan et al., 2016b). This red-heart characteristics also increases the value of red-heart Chinese fir, compared with other $C$. lanceolata varieties. The timber of $S$. sempervirens with red-heart wood is also highly valued and widely used because of its natural durability, attractive color and dimensional stability

Table 3. Comparison of the effects of red-heart wood on wood value in different tree species

\begin{tabular}{lcc}
\hline \multicolumn{1}{c}{ Tree species } & Results: effects of red-heart wood & References \\
\hline Red-heart Chinese fir & Increased commercial value & Duan et al., 2016b \\
Huang et al., 2006 & Highly valued & Davies et al., 2014 \\
$\begin{array}{l}\text { Sequoia sempervirens } \\
\text { (Coastal redwood) }\end{array}$ & Increased commercial value \\
$\begin{array}{l}\text { Lechang Chinese fir } \\
\text { Fagus sylvatica L. (European beech) }\end{array}$ & Use limited; decreased value & Duan et al., 2016b \\
& & Knoke, 2003 \\
$\begin{array}{l}\text { Populus simonii var.przewalskii } \\
\text { Pseudotsuga menziesii (Mirb.) Franco (Douglas fir) }\end{array}$ & Decreased wood quality and value & Wernsdorfer et al., 2005 \\
\hline
\end{tabular}


(Davies et al., 2014). Pseudotsuga menziesii (Douglas-fir) has desirable wood properties and is disease resistant. It is an important commercial tree species in Central Europe (Essl, 2005; Schmid et al., 2014) that has reddish-brown heartwood which is generally not sensitive to insect damage; the timber is increasingly used outside for wood coverings and joinery (Da Ronch et al., 2016). In most tree species, this red-heart character that develops naturally is desirable; for example, Larix gmelinii (Rupr.) Kuzen (larches) and Quercus palustris (oaks) (Puech et al., 1999; Gierlinger et al., 2004). However, in some other tree species, such as F. sylvatica L. (European beech), the characteristics of "red heartwood" (brown, grey, green or even purple color) decrease timber value when compared to those of white color heartwoods (Knoke, 2003; Wernsdorfer et al., 2005; Pöhler et al., 2006). Some studies have reported no difference between the mechanical properties of red-heart and non-red-heart wood; research on the red-heart wood of Populus simonii var. przewalskii, however, has led to the suggestion that it is of inferior quality compared to white heartwood (An, 1979; Knoke, 2002; Duan et al., 2016ab; Racko et al., 2015).

\section{Red-heart Chinese fir wood utilization}

The cultigen Chenshan red-heart Chinese fir trees grown in Chenshan are 'well-known throughout China, and produce better timber than trees from Southeast Asia' (Yu, 1997a). This conifer has been used in the construction of palaces since antiquity, and was utilized, for example, in the construction of the Chairman Mao Memorial Hall. In addition to being a medicinal and ornamental tree (Wu et al., 2011b), red-heart Chinese fir became a favored material for wooden flooring throughout the country, because of higher red-heart ratio and its aroma. It is also commonly used in the production of decorative objects. The high-value applications of wood from this conifer should be the focus for future research on this cultigen.

\section{Conclusion}

Elite germplasm collection and conservation has not been optimized, and the compilation and maintenance of red-heart Chinese fir seed orchards has not yet been achieved. The embryonic callus culture technique that should be used for red-heart Chinese fir also remains immature, and there are many problems with traditional breeding. Nevertheless, it is hoped that future work will solve the vegetative propagation problem, so that the cultivation of red-heart Chinese fir can be enhanced to satisfy the growing demand from the timber market.
Red-heart Chinese fir is a specific C. lanceolata variant, thought to have originated via the genome-environment interactions. Just a handful of research have been carried out to date on the mechanisms of red-heart wood formation in Chinese fir, but these studies were not in-depth and have mainly been concerned with chemical composition. No study has so far been carried out to investigate the effect of soil properties on the formation of red-heart wood, but such problems will become the focus of ecological research. For example, it is of interest whether there is any relationship between the high red-heart ratio of red-heart Chinese fir and the local iron mine. This is of interest because the Chenshan region, which is the main production region for red-heart Chinese fir, was also an iron mining area. We plan to carry out more research on the relationship between iron and the red-heart ratio of red-heart Chinese fir.

As a number of studies have been carried out on redwoods from China and other countries, variable findings have been reported. For example, while the appearance of the red-heart character in P. simonii var. przewalskii and F. sylvatica decreases timber quality and wood value, this characteristics in red-heart Chinese fir and in P. massoniana had the opposite effect. Future studies should proceed to investigate the relationship between the formation of red-heart in Chinese fir and properties of cell walls, as well as the physiological activity of the cambium and tracheids (Song et al., 2011, 2014).

Although studies have been performed on the chemical composition of red-heart Chinese fir, these have not focused on the red-heart wood itself. Relationships among the genome, environment, and the formation of red-heart Chinese fir are therefore important gaps in current research efforts. Future research would directly address relationships between the formation of red heartwood, its chemical composition, and genetic characteristics, as well as underlying environmental factors.

\section{Acknowledgments}

The authors would like to thank The National Key Research and Development Program of China (2016YFD0600303) for its financial support. Daniel J. Chmura provided critical feedback that improved an earlier version of our manuscript.

\section{References}

An PJ (1979) The impact of Populus tomentosa redheart on the wood property and its utilization. Shaanxi Forest Science and Technology 1: 46-53. 
Bao FC (1998) Wood properties of main tree species from plantation in China. China Forestry Publishing, Beijing, China.

Bi J, Blanco JAB, Seely BS, Kimmins JP, Ding Y \& Welham C (2002) Yield decline in Chinese-fir plantations: a simulation investigation with implication for model complexity. Canadian Journal of Forest Research 37: 1615-1630. doi:10.1139/ X07-018.

Cardoso EJBN, Vasconcellos RLF, Bini D, Miyauchi MYH, Santos CAD, Alves PRL, Paula AMD, Nakatani AS, Pereira JDM \& Nogueira MA (2013) Soil health: looking for suitable indicators. What should be considered to assess the effects of use and management on soil health? Scientia Agricola 70: 274-289. doi:10.1590/S010390162013000400009.

Chen HJ (1998) Biomass and nutrient distribution in a Chinese-fir plantation chronosequence in southwest Hunan, China. Forest Ecology and Management 105: 209-216. doi:10.1016/S03781127(97)00284-3.

Chen LC \& Wang SL (2013) Allelopathic behaviour of Chinese fir from plantations of different ages. Forestry 86: 225-230. doi:10.1093/forestry/ cps078.

Chen Q, Huang KY, Lan X, Dai J \& He HK (2012) Research advances of tissue culture techniques for Cunninghamia lanceolata in China. World Forestry Research 25: 58-63. doi:10.13348/j.cnki. sjlyyj.2012.06.011.

Chen YW \& Shi JS (1983) Some fundamental problems in genetic improvement of Chinese fir. Journal of Nanjing Technological College of Forest Products 4: 5-19.

Cheng JQ (1985) Xylology. China Forestry Publishing House, Beijing, China.

Davies NT, Wu HF \& Altaner CM (2014) The chemistry and bioactivity of various heartwood extracts from redwood (Sequoia sempervirens) against two species of fungi. New Zealand Journal of Forestry Science 44: 17. doi:10.1186/s40490-014-0017-4.

Dong M, Xu, YM, Lin H, Li XQ \& Xia QQ (2016) Seasonal dynamics in cambial activity and the formation of xylem and phloem in the branches of Cinnamomum camphora. Dendrobiology 75: 13-21. doi:org/10.12657/denbio.075.002.

Ding YX \& Chen JL (1995) Effect of continuous plantation of Chinese fir on soil fertility. Pedosphere 5: 57-66.

Duan H, Cao S, Zheng HQ, Hu DH, Lin J, Lin HZ, Hu RY, Sun YH \& Li Y (2016a) Variation in the growth traits and wood properties of Chinese fir from six provinces of southern China. Forests 7: 192. doi:10.3390/f7090192.

Duan H, Hu D, Li Y \& Zeng HQ (2016b) Characterization of a collection of Chinese fir elite genotypes using sequence-related amplified polymor- phism markers. Journal of Forestry Research 27: 1105-1110. doi:10.1007/s11676-016-0233-2.

Duan HJ, Hu RY, Wu B, Chen DX, Huang KY, Dai J, Chen Q, Wei ZC, Cao S, Sun YH \& Li Y (2015) Genetic characterization of red-colored heartwood genotypes of Chinese fir using simple sequence repeat (SSR) markers. Genetics \& Molecular Research 14: 18552-18561. doi:org/10.4238/2015. December.28.2.

Fan GR, Wang ZD \& Peng DY (2001) A study on the world's chemical composition of Chenshan red-heart Chinese fir. Jiangxi Forestry Science and Technology 2: 4-5. doi:10.16259/j.cnki.36-1342/s.2001.02.003.

Fan GR, Zhang WY, Xiao FM, Zhu XZ, Jiang XM \& Li YS (2015) Studies on longitudinal variation of main chemical components in Chenshan red-heart Chinese fir. Acta Agriculturae Universitatis Jiangxiensis 37: 212-217. doi:10.13836/j. jjau.2015032.

Fang JY, Chen AP, Peng CH, Zhao SQ \& Ci L (2001) Changes in forest biomass carbon storage in China between 1949 and 1998. Science 292: 23202322.

Fu LG, Yu YF \& Mill RR (1999) Taxodiaceae: Flora of China, vol. 4 (ed. by ZY Wu \& PH Raven) Science Press, Beijing, China, Missouri Botanical Garden Press, St. Louis, USA, pp. 54-61.

Gierlinger N, Jacques D, Grabner M, Wimmer R, Schwanninger M, Rozenberg $\mathrm{P}$ \& Pâques LE (2004) Colour of larch heartwood and relationships to extractives and brown-rot decay resistance. Trees 18: 102-108. doi:10.1007/s00468003-0290-y.

Guo YR, Wang WL, Yang YC, Zhang YJ, Duan QM, Zhang JL \& You T (2014) Effects of four trace elements on the morphogenesis and stress resistance of Astragalus membranaceus (Fisch.) Bge. var. mongholicus (Bge) Hsiao. Acta Agriculturae Boreali-Occidentalis Sinica 23: 172-179. doi:10.7606/j. issn.1004-1389.2014.06.026.

Halbritter A \& Deegen P (2011) Economic analysis of exploitation and regeneration in plantations with problematic site productivity. Journal of Forest Economics 17: 319-334. doi:10.1016/j. jfe.2011.02.003.

Huang BL \& Lan TG (1988) Preliminary study on cultural history of Chinese fir. Journal of Nanjing Forestry University 2: 54-59.

Huang BX, Fu SH \& Zhu PL (2009) Proliferation culture of embryonic callus of Chenshan red-heart Chinese fir. Jiangxi Forestry Science and Technology 5: 8-9. doi:10.16259/j.cnki.36-1342/s.2009.05.012.

Huang YQ, Lin J, Ruan ZC \& Lai XE (2006) A study on collection conservation and utilization for gene resource of Cunninghamia lanceolata in Guangdong 
province. Guangdong Forestry Science and Technology 22: 128-132.

Huang ZQ, Liao LP, Wang SL \& Cao GQ (2000) Allelopathy of phenolics from decomposing stump-roots in replant Chinese fir woodland. Journal of Chemical Ecology 26: 2211-2219. doi:10.1023/A:1005580718765.

Knoke T (2002) Value of complete information on red heartwood formation in beech (Fagus sylvatica L.). Silva Fennica 36: 841-851. doi:10.14214/ sf. 525 .

Knoke T (2003) Predicting red heartwood formation in beech trees (Fagus sylvatica, L.). Ecological Modelling 169: 295-312. doi:10.1016/S03043800(03)00276-X.

LeBauer DS \& Treseder KK (2008) Nitrogen limitation of net primary productivity in terrestrial ecosystems is globally distributed. Ecology 89: 371-379. doi:10.1890/06-2057.1.

Lei H (1988) Compared research for the woodstructure and properties of two C. lanceolate variants (In Chinese). Journal of Central South University of Forestry \& Technology 8: 208-217. doi:10.14067/j.cnki.1673-923x.1988.02.018

Li LC (1989) Studies on the cytotaxonomy and systematic evolution of Taxodiaceae warming. Acta Botanica Yunnanica 11: 113-131.

Li YQ, Deng XW, Huang ZH, Xiang WH, Yan WD, Lei PF, Zhou XL \& Peng CH (2015) Development and evaluation of models for the relationship between tree height and diameter at breast height for Chinese-fir plantations in subtropical China. PLoS One 10: e0125118. doi:10.1371/journal. pone.0125118.

Liang WY (2010) The cutting propagation technique and afforestation experiment of Cunninghamia konishii. Subtropical Agriculture Research 06: 217-221. doi:10.13321/j.cnki.subtrop.agric. res.2010.04.015.

Liu Y \& Zhong LT (2013) Study on chemical components of essential oil in heartwood of Chinese fir. Journal of Central South University of Forestry \& Technology 33: 119-125. doi:10.14067/j.cnki.1673-923x.2013.12.033.

Luo LC \& Xu LF (1985) Research on the physico-mechanical properties of $C$. lanceolata that grew in Yunnan Province (In Chinese). Yunnan Forestry Science and Technology 2: 1-14. doi:10.16473/j. cnki.xblykx1972.1985.02.001.

Ma XQ (2014) The kings of Chinese fir. China Forestry Publishing House. Beijing, China.

Ma XQ \& Fan FR (1993) The evolution and thinking of Chinese fir cultivation system. Issues of Forestry Economics 4: 60-62. doi:10.16832/j. cnki.1005-9709.1993. 04.015.

Mo DT (2014) Afforestation technology of Red-heart Chinese fir. Scientific Farming 7: 162.
O’Hehir JF \& Nambiar EKS (2010) Productivity of three successive rotations of $P$. radiata plantations in South Australia over a century. Forest Ecology \& Management 259: 1857-1869. doi:10.1016/j. foreco.2009.12.004.

Pirard R, Secco D \& Warman R (2016) Do timber plantations contribute to forest conservation? Environmental Science \& Policy 57: 122-130. doi:10.1016/j.envsci. 2015.12.010.

Pöhler E, Klingner R \& Künniger T (2006) Beech (Fagus sylvatica L.) - technological properties, adhesion behaviour and color stability with and without coatings of the red heartwood. Annals of Forest Science 63: 129-137. doi:10.1051/forest:2005105.

Puech JL, Feuillat F \& Mosedale JR (1999) The tannins of oak heartwood: Structure, properties, and their influence on wine flavor. American Journal of Enology and Viticulture 50: 469-478.

Qin TF, Huang LH \& Zhou Q (2004) Studies on longitudinal variation of main chemical compositions in Chinese fir and Poplar $\times$ euramaricana cV. I-72/58 trees. Forest Research 17: 47-53. doi:13275/j.cnki.lykxyj.2004.01.008.

Racko V, Cunderlik I \& Saniga M (2015) Influence of silvicultural strategies on red heartwood occurrence in beech (preliminary study). Wood Research 60: 11-24.

Shi JS, Ye ZH, Weng YZ, Xu RZ, Li SM, Chen XR, Liu DL, Zhang FS \& Li YK (1993) Research on the joint genetic improvement of growth and wood properties in Chinese fir (Cunninghamia lanceolata (Lamb.) Hook.). Journal of Nanjing Forestry University 17: 1-8.

Song K, Liu B, Jiang X \& Yin Y (2011) Cellular changes of tracheids and ray parenchyma cells from cambium to heartwood in Cunninghamia lanceolata. Journal of Tropical Forest Science 23: 478-487.

Song K, Yin Y, Salmén L, Xiao F \& Jiang X (2014) Changes in the properties of wood cell walls during the transformation from sapwood to heartwood. Journal of Materials Science 49: 17341742. doi:10.1007/s10853-013-7860-1.

Sun JB, Yang H, Liu YS \& Zhang LX (2013) Study on correlation between volatile oil and rhizosphere soil from roots of Saposhnikovia divaricata. Chinese Traditional and Herbal Drugs 44: 891-895. doi:10.7501/j.issn. 0253-2670.2013.07.022.

State Forestry Administration of China (2014) The statistics of the eighth continuous survey of national forest resource. http://data.forestry.gov. $\mathrm{cn} /$ lysjk/indexJump.do? $\mathrm{url}=$ view/moudle/dataQuery/dataQuery.

Tang XL, Lu YC, Fehrmann L, Forrester DI, Guisasola-Rodríguez R, Pérez-Cruzado C \& Kleinn C (2016) Estimation of stand-level aboveground biomass dynamics using tree ring analysis in 
a Chinese fir plantation in Shitai County, Anhui Province, China. New Forests 47: 319-332. doi:10.1007/s11056-015-9518-0.

Tian DL (2005) The functioning of Chinese fir plantation ecosystem. Science Press, Beijing, China.

Tian DL, Xiang WH, Chen XY, Yan WD, Fang X, Kang WX, Dan XW, Peng CH \& Peng YY (2011) A longterm evaluation of biomass production in first and second rotations of Chinese fir plantations at the same site. Forestry 84: 411-418. doi:10.1093/ forestry/ cpr029.

Vek V, Primož O \& Poljanšek I (2013) Content of total phenols in red heart and wound-associated wood in beech (Fagus sylvatica L.). Drvna Industrija 64: 25-32. doi:10.5552/drind.2013.1224.

Verheyen K, Vanhellemont M, Auge H, Baeten L, Baraloto C, Barsoum N, Bilodeau-Gauthier S, Bruelheide H, Castagneyrol B, Godbold D, Haase J, Hector A, Jactel H, Koricheva J, Loreau MZ, Mereu S, Messier C, Muys B, Nolet P, Paquette A, Parker J, Perring M, Ponette Q, Potvin C, Reich P, Smith A, Weih M \& Scherer-Lorenzen M (2016) Contributions of a global network of tree diversity experiments to sustainable forest plantations. Ambio 45: 29-41. doi:10.1007/s11427012-4359-y.

Wen XD, Zhao ZH, Deng XW, Xiang WH, Tian DL, Yan WD, Zhou XL \& Peng CH (2014) Applying an artificial neural network to simulate and predict Chinese fir (Cunninghamia lanceolata) plantation carbon flux in subtropical China. Ecological Modelling 294: 19-26. doi:10.1016/j.ecolmodel.2014.09.006.

Wernsdorfer $\mathrm{H}$, Constant $\mathrm{T}$, Mothe $\mathrm{F}$, Badia MA, Nepveu G \& Seeling U (2005) Detailed analysis of the geometric relationship between external traits and the shape of red heartwood in beech trees ( $\mathrm{Fa}$ gus sylvatica L.). Trees 19: 482-491. doi:10.1007/ s00468-005-0410-y.

Wood JM (2004) Net primary productivity of macrophyte communities after ten growing seasons in experimental marshes. Olentangy River Wetland Research Park 250: 4477-4485.

Woods RV (1990) Second rotation decline in P. radiata, plantations in south Australia has been corrected. Water, Air, and Soil Pollution 54: 607-619. doi:10.1007/BF02385158

Wu HY, Xu HM, Li HY, Wei DM, Lin JX \& Li XJ (2016) Seasonal development of cambial activity in relation to xylem formation in Chinese fir. Journal of Plant Physiology 195: 23-30.

Wu PW, Ma XM, Tigabu MT, Wang CW, Liu AL \& Odén COC (2011a) Root morphological plasticity and biomass production of two Chinese fir clones with high phosphorus efficiency under low phosphorus stress. Canadian Journal of Forest Research 41: 228-234. doi:10.1139/X10-198.
Wu SB, Liu JY \& Yan QS (2011b) Study on dissolving out law and physical and chemical properties of elm phloem extractives. Paper Science \& Technology 30: 1-9.

Wu YF, Xu HN, Xiao FM, Xiong ZY \& Jiang XM (2012) Comparative research on isolation and purification method for genomic DNA of Cunninghamia lanceolata. Acta Agriculturae Universitatis Jiangxiensis 34: 517-521.

Xia ZC, Kong CH, Chen LC \& Wang SL (2015) Allelochemical-mediated soil microbial community in long-term monospecific Chinese fir forest plantations. Applied Soil Ecology 96: 52-59. doi:10.1016/j.apsoil.2015.07.012.

Xu BS \& Fang YX (1986) Karyological studies in Cunninghamia unicanaliculata and var. pyramidalis. Acta Botanica Sinica 28: 150-155.

Xu SF \& Wu LX (1987) Contrast research for the photosynthetic rate of Cunninghamia lanceolata 'Youshan' and C. lanceolata 'Mangshan'. Hunan Forestry Science \& Technology 1: 19-21.

Xu T, Wang H, Zhu W, Wang Y, Li C \& Jiang Y (2015) Morphological and anatomical traits of poplar fine roots in successive rotation plantations. Scientia Silvae Sinicae 51: 119-126 doi:10.11707 /j.1001-7488.20150114.

Xu YY, Du PL, Liu XQ, Wei SJ, Jiang WX \& Yang M (2016a) Effects of various stroma and root agent on seedling rooting and chlorophyll fluorescence parameters in Cunninghamia lanceolata. Journal of Beihua University (Natural Science) 17: 530-536. doi:10.11713/j.issn.1009-4822.2016.04.025.

Xu YZ, Du CQ, Xu XY, Hu YX, Zhang YD, Xu XH, Huang GW \& Fang LQ (2016b) A new variety of Cunninghamia lanceolata 'E Sha 1'. Scientia Silvae Sinicae 52: 170-170.

Yang HK, Wen SF, Xiao FM \& Fan GR (2016) Study on the chemical compositions of ethanol extraction from Chenshan red-heart Chinese fir. Jiangxi Forestry Science and Technology 44: 35-37.

Yang XF \& Zeng ZG (2003) Exploring the industrialization development of good Cunninghamia lanceolata 'Chenshan red-fir'. China Forestry Science and Technology 17: 57-58.

Ye Z, Lin WX, Chen W \& Yu XT (2005) Chemical components and antimicrobial activity of essential oils in Cunninghamia lanceolata heartwood. Chinese Journal of Applied Ecology 16: 2394-2398.

Yu JB (1997a) Chenshan forest farm and Chinese "Emperor Wood". Jiang Xizheng quote.

Yu XT (1997b) Chinese fir culture. Science and Technology Press, Fujian, China.

Yu XT, Ye GF \& Lu J (1997) Approaching the cultural system development of Cunninghamia lanceolata. Journal of Fujian Forestry \& Technology 24: 1-5. 
Yu XT, Ye GF, Lin SZ \& He ZY (1992) An approach to the culture system for Chinese fir. Journal of Forest and Environment 12: 251-258.

Yu YF (1994) Taxonomic studies on the family Taxodiaceae. Bulletin of Botanical Research 14: 369382.

Zeng ZG \& Jiang XZ (2012) Good Chinese fir species "Chenshan Red-heart Chinese Fir" and its cultivation technology. Rural Blackstone 15: 28-30.

Zhang Q (1997) Effects of soil extracts from repeated plantation woodland of Chinese-fir on microbial activities and soil nitrogen mineralization dynamics. Plant and Soil 191: 205-212. doi:10.1023/A:1004246906869.

Zhang X, Duan A \& Zhang J (2013) Tree biomass estimation of Chinese fir (Cunninghamia lanceolata) based on bayesian method. PLoS One 8: e79868. doi:10.1371/journal.pone. 0079868.

Zhang ZW (2003) Researching for clone pollen activity and pollen germination performance in Chongyang Chinese fir orchard. Seed 5: 79-80. doi:10.16590/ j.cnki.1001-4705.2003.05.091. 